\title{
VARNOST STAVB OB TERORISTIČNEM BOMBNEM NAPADU
}

\author{
SECURITY OF BUILDINGS IN THE EVENT \\ OF A TERRORIST BOMB ATTACK
}

Povzetek Teroristične organizacije pogosto izvajajo bombne napade v bližini objektov, $\mathrm{v}$ katerih se ljudje zbirajo. Eksplozija v bližini stavbe ima lahko na stavbo katastrofalne učinke in lahko povzroči progresivno rušenje stavbe. Da bi ugotovil, kako varne so stavbe ob eksploziji, sem v članku s praktično računsko metodo pokazal učinke eksplozije in odziv gradbene konstrukcije glede na oddaljenost vira eksplozije in količine eksplozivnega sredstva. Preprečevanje progresivnega rušenja zgradbe, izpostavljene eksploziji, je glavni način obvarovanja stavb pred učinki eksplozije, to pa najlažje zagotovimo z vzpostavitvijo varnostne razdalje. Tako se prepreči možnost približevanja vira eksplozije v bližino stavb.

Ključne Teroristični napad, eksplozija, udarni val, obtežba eksplozije, varnostna razdalja.

besede

Abstract Terrorist organizations often carry out attacks in the vicinity of buildings that serve as gathering points. A blast in the vicinity of any construction may have catastrophic consequences and can lead to progressive collapse of the building. In order to determine the level of safety of buildings in the event of a blast, I used a practical calculation method of blast effect and a structural response of buildings, depending on the amount of explosive used and its distance from the target. The main method to protect buildings, exposed to a blast, from effects of a blast is to prevent their progressive collapse. The easiest way to do this is to establish a safe distance, which prevents the source of a blast from getting close to a building.

Key words Terrorist attack, blast, blast wave, blast load, safe distance. 
Uvod Zgradbe so od časov sodobnega vojskovanja izpostavljene bombnim eksplozijam, v zadnjih letih pa smo priča, ko zaradi groženj terorističnih napadov na zgradbe največjo nevarnost predstavljajo morebitni bombni napadi. Teroristične organizacije za dosego svojih ciljev največkrat uporabljajo improvizirana eksplozivna sredstva. Vse več je pobud za raziskave odpornosti gradbenih konstrukcij, obremenjenih z eksplozijo. Poleg tega potekajo številne raziskave in projekti, da bi razvili mehanizme ter sisteme za zmanjšanje posledic tovrstnih napadov, katerih glavni cilj je zagotoviti varnost ljudi v zgradbah. Ena izmed glavnih zakonitosti zagotavljanja zadostne robustnosti zgradb je preprečevanje progresivnega rušenja zgradbe, izpostavljene eksploziji. Z gradbenega vidika je treba zagotoviti konstrukcijski sistem, ki lahko prenese teroristični bombni napad brez poškodb ali z minimalno škodo. Objekti, ki bi morali biti grajeni tako, da bi prenesli obremenitev eksplozije, so predvsem objekti državnega pomena, ki bi se morali uporabljati tudi po bombnem napadu. Gradnja takih objektov zahteva veliko denarja, poleg tega pa se za dosego takih ciljev lahko zelo spremeni videz objektov, v nekaterih primerih pa tudi funkcionalnost objekta. Civilni objekti tako visokih stroškov ne prenesejo, vendar pa obstaja tudi zelo majhna verjetnost, da bo prišlo do terorističnega napada na tovrstne objekte. Na podlagi nekaterih študij (Bosiljkov, 2009, in Hinman, 2009) se je pokazalo, da imajo ukrepi za zagotovitev potresne odpornosti armiranobetonskih objektov lahko, ni pa nujno, tudi pozitivne učinke pri objektih, izpostavljenih eksplozijam.

Eksplozija kot izjemna obremenitev (v nadaljevanju povzeto po Carino, 2001) ob dogodku ustvari na konstrukcijo določeno obtežitev, ki je po nekaterih svojih lastnostih primerljiva z nam bolj znano potresno obtežitvijo. Pri teh dveh obtežitvah gre za povsem različni ekstremni sili, zaradi katerih se lahko ruši konstrukcija, pri obeh obtežitvah pa gre za dinamično obtežitev, dinamičen pa je tudi odziv konstrukcije. Pri obtežitvi eksplozije udarni val ustvari neposredno obtežitev na konstrukcijo, pri potresu pa se ustvari obtežitev, ki je posledica tresenja tal. Tudi ob eksploziji se tla tresejo, vendar je ta del obtežitve razmeroma zanemarljiv. Obtežitev eksplozije v primerjavi s potresno obtežbo traja zelo kratek čas, učinek delovanja eksplozije v primerjavi s potresom pa je lokalen. Sposobnost ohranjanja lokalnih poškodb brez popolne porušitve je bistvena podobnost med seizmično odpornostjo konstrukcij in odpornostjo konstrukcij pri delovanju eksplozije.

\section{SPLOŠNO O EKSPLOZIJI}

Poznamo fizikalne, jedrske, električne in kemične eksplozije. V nadaljevanju bom obravnaval le kemične eksplozije, saj so eksplozivne snovi kemične substance ali zmesi kemičnih substanc (Mays, 1995).

Kemična eksplozija je proces zelo hitrega zgorevanja kemične substance (v nadaljevanju povzeto po Mays, 1995, str. 27), pri katerem nastanejo velike količine plinastih produktov, segretih do visokih temperatur, zaradi česar se v okolju eksplozije zelo poveča tlak. V zelo kratkem času se sprosti veliko toplotne energije, ki se spremeni v mehansko delo. Pri detonaciji eksploziva si sledijo naslednji dogodki. 
Eksplozivna reakcija ustvari vroče pline, ki so lahko pod pritiskom od 10.000 do $30.000 \mathrm{MPa}$ (megapascal) in dosegajo temperaturo od 3000 do $4000{ }^{\circ} \mathrm{C}$. Nato pride do širitve teh plinov, zato se mora zrak v okolici umakniti. Posledica tega procesa je plast stisnjenega zraka oziroma udarni val, ki nastane pred temi plini in vsebuje večino energije, sproščene pri eksploziji. Udarni val se nato sferično širi navzven od vira eksplozije, različne vrste tlaka na kraju eksplozije pa padejo na raven tlaka atmosfere. $\mathrm{Z}$ naraščajočo razdaljo se znižuje tudi tlak stisnjenega zraka na čelu udarnega vala. Plin se še naprej razširja, poleg tega se tudi ohlaja, tlak v okolici vira eksplozije pa pade malo pod atmosferski tlak. Rezultat čezmerne širitve plinov je sprememba smeri vala eksplozije, saj se ta zaradi majhne razlike v atmosferskem tlaku in tlaku plinov začne gibati proti viru eksplozije. To obdobje imenujemo negativna faza udarnega vala eksplozije. Potiskanje zraka in plinov stran od vira eksplozije se nato neha in sčasoma se razmere vrnejo v ravnovesje.

Na spodnjem grafu je prikazana časovna sprememba različnih vrst tlaka eksplozije, pri čemer so:

$t-\check{c}$ as

$t_{\mathrm{a}}$ - čas prihoda čelnega udarnega vala

$p_{\text {s }}$-pozitivni tlak eksplozije

$\Delta \mathrm{p}_{\text {min. }}$ - negativni tlak eksplozije

$T_{\text {s }}$-trajanje pozitivne faze eksplozije

$p_{0}$-atmosferski tlak

$i_{\mathrm{s}}$-specifičen stranski impulz vala

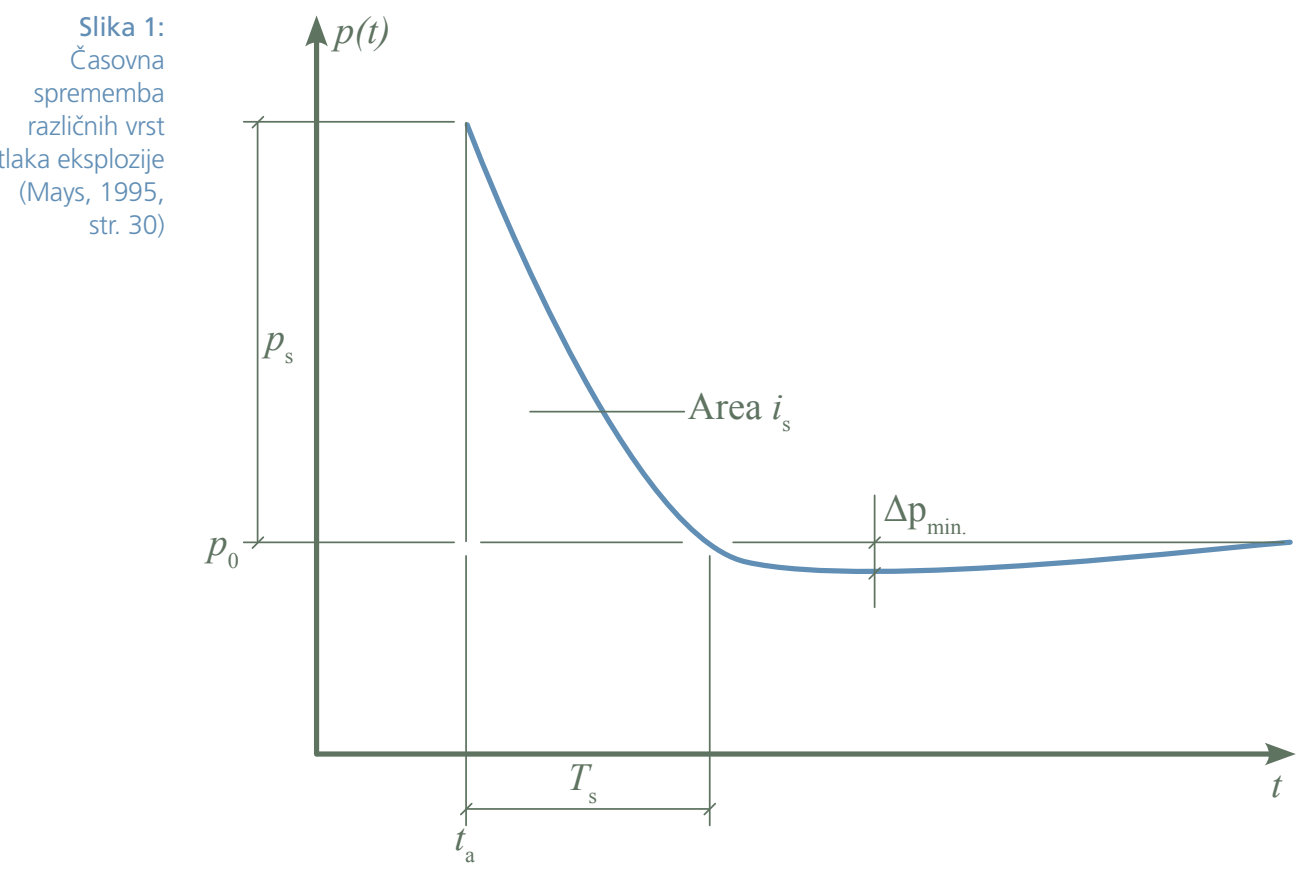




\section{DELOVANJE UDARNEGA VALA EKSPLOZIJE NA OBJEKT}

Udarni val je posledica eksplozije in povzroči delovanje velike sile v zelo kratkem času. Velikost udarnega vala eksplozije je obratno sorazmerna z oddaljenostjo od središča eksplozije (Carino, 2001).

Ob eksploziji v bližini stavbe se udarni val eksplozije približuje objektu in ga najprej zadane s sprednje, čelne strani objekta. Vpliv udarnega vala bo na izpostavljeno površino. Udarni val eksplozije bo na objekt deloval tako, da bo pritiskal na površino v smeri delovanja udarnega vala eksplozije, dokler bo udarni val deloval na sprednjo, čelno stran objekta. Udarni val se nato odbije od sprednje, čelne strani objekta, del udarnega vala, ki preide objekt ob strani in vrhu objekta, nato na zadnji strani objekta deluje tako, da povzroča srk (Glasstone, 1977).
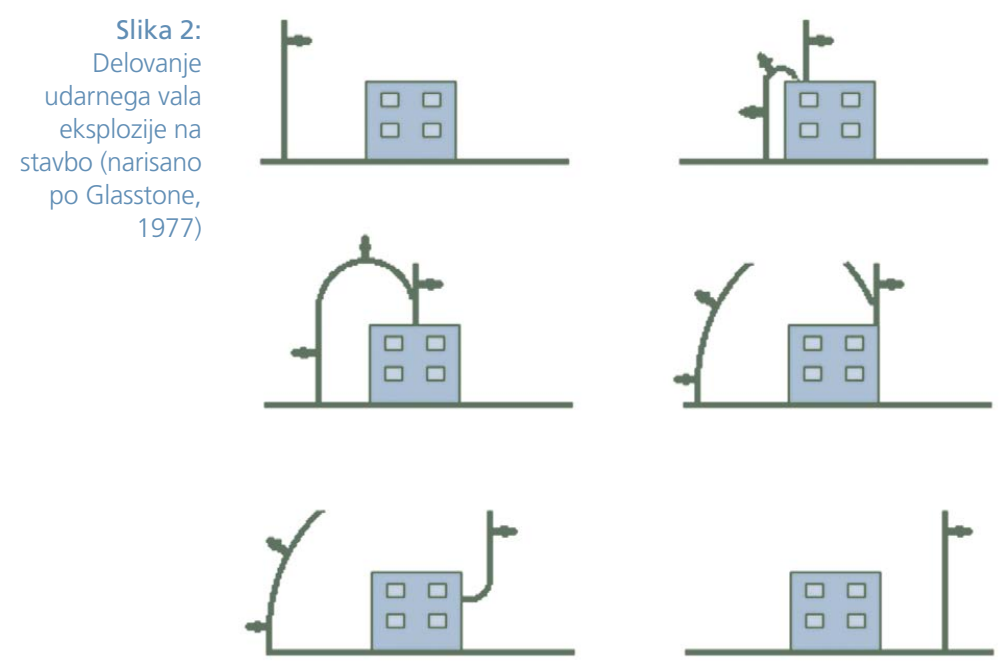

Hitrost, s katero udarni val potuje po ozračju, imenujemo hitrost čelnega udarnega vala eksplozije, enota pa je $\mathrm{m} / \mu \mathrm{s}$. Najvišji tlak udarnega vala $\left(\mathrm{p}_{\mathrm{s}}\right)$ pri detonaciji eksploziva, ki je postavljen na tleh, se meri v barih. Pri dimenzioniranju določenih elementov je poleg tlaka eksplozije treba upoštevati tudi rezultirajoči impulz eksplozije. Impulz udarnega vala eksplozije je vsa energija eksplozije, enote pa $\mathrm{kPa} \mu \mathrm{s}$. Odvisen je od tlaka eksplozije in časa trajanja obtežitve (Mays, 1995).

Pri srečanju udarnega vala z neskončno trdno površino se bo ta od trdne površine odbil, od geometrijske oblike in velikosti objekta pa je odvisno, kako se bo udarni val odbil. Nekatere geometrijske oblike objektov lahko tako le še povečajo učinek udarnega vala eksplozije, obstajajo pa tudi geometrijske oblike objektov, ki ta učinek zmanjšajo (Hinman, 2009). 
Slika 3:

Oblike objektov,

ki povečajo

učinek udarnega

vala eksplozije

(narisano po

Hinman, 2009)
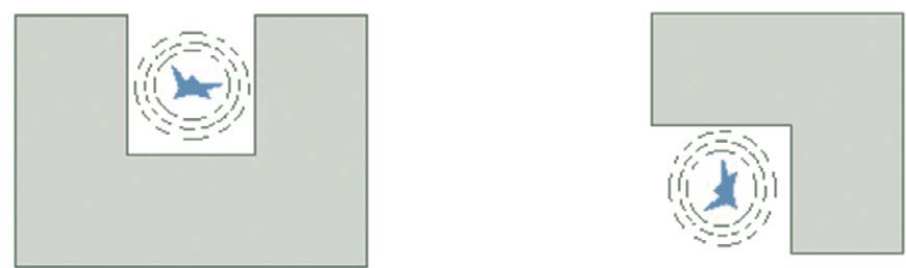

Slika 4: Oblike objektov, ki zmanjšajo učinek udarnega vala eksplozije (narisano po Hinman, 2009)
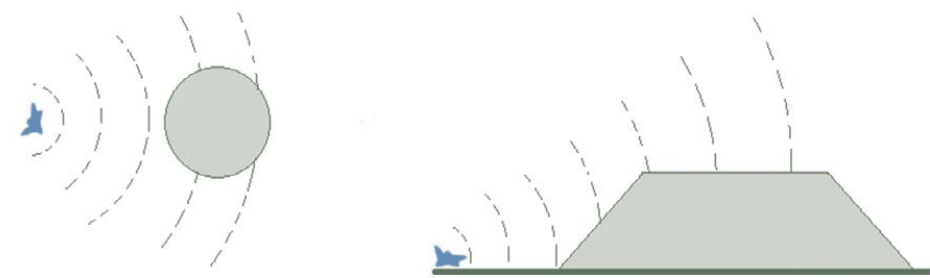

\section{STANDARDI ZA DIMENZIONIRANJE STAVB, KI BI JIH ŽELELI ZAŠČITITI PRED DELOVANJEM EKSPLOZIJE}

V okviru evrokodov ${ }^{1}$ ni nobenih standardov za izračun odpornosti konstrukcije glede na obremenitev zaradi eksplozije. Eksplozije so (SIST EN 1991-1-7) definirane kot nezgodno projektno stanje. V okviru evrokodov je omenjeno le zagotavljanje robustnosti konstrukcije ob eksploziji plinskih jeklenk. Pri tovrstnih dogodkih je treba zagotoviti, da lokalna zrušitev konstrukcijskega elementa ne povzroči progresivne rušitve celotne konstrukcije.

V nadaljevanju so opisani protiteroristični standardi s področja stavb (UFC 4-010-01, 2003), razviti pa so bili na oddelku za obrambo Združenih držav Amerike. Vključujejo merila na področju načrtovanja, projektiranja, gradnje, posodobitve in obnove stavb. Ti standardi so kombinacija zahtev in predpisov. Merila so določena, da bi z njimi ublažili posledice bombnih terorističnih napadov. Večina stavb zagotavlja majhno zaščito pred bombnimi napadi. Z uporabo teh standardov zmanjšamo materialno škodo in preventivno obvarujemo človeška življenja. Pri načrtovanju zgradb pred uničujočim delovanjem eksplozije je treba upoštevati osnovna navodila za načrtovanje takšnih objektov.

Evrokodi so standardi, ki določajo načela in pravila za zagotovitev varnosti, uporabnosti in trajnosti objektov, opisujejo osnove njihovega projektiranja ter preverjanja in dajejo usmeritve za dosego navedenih vidikov zanesljivosti objektov. 
- Zagotoviti zadostno razdaljo med virom eksplozije in objektom: Primarna naloga načrtovanja je preprečitev možnosti približanja vira eksplozije objektu. To je najlažji in najcenejši način obvarovanja objekta pred učinki eksplozije.

- Preprečitev porušenja objekta: Za preprečevanje smrtnih žrtev je zelo pomembno, da ne pride do progresivnega rušenja objektov. Pri objektu ne sme priti do progresivnega rušenja, ne glede na to, kakšna je razdalja med virom eksplozije in objektom ali kako se objekt odzove na obtežitev.

- Izbira primernega materiala: Kadar se ob eksploziji ne poruši celoten objekt, lahko razbitine stekla oziroma delov konstrukcije povzročijo veliko smrtnih žrtev. Za zmanjševanje takšne nevarnosti je treba v objekt vgrajevati ustrezen material.

- Izbira lokacije objekta: Primerna lokacija objekta lahko močno zmanjša možnost bombnega napada.

- Omogočena nadgradnja objektov: Ob povečanju nevarnosti bombnega napada na območju, kjer je objekt, mora ta omogočati tako nadgradnjo, da bo objekt ob bombnem napadu varen.

Natančna določila so opredeljena v standardih. V njih je vse od načrtovanja stavb do načrtovanja njihove okolice in pripadajoče infrastrukture, ki je pomembna za delovanje stavbe. V nadaljevanju so opisani standardi, ki predvidevajo kemično eksplozijo v bližnji okolici objekta.

Najpomembnejši standard je tisti, ki določa minimalno razdaljo med virom eksplozije in objektom. To je stroškovno najbolj učinkovita rešitev. Omenjeno razdaljo zagotovimo tako, da onemogočimo, da so eksplozivna sredstva aktivirana $\mathrm{V}$ bližini objektov. Z različnimi rešitvami poskušamo zadržati aktiviranje eksplozivnih sredstev zunaj varnostne razdalje med virom eksplozije in objektom. Standard v nadaljevanju določa varnostno razdaljo za objekte, ki so bili grajeni brez posebnih načrtovanj za objekte, obremenjene z eksplozijo. Varnostne razdalje, ki jih določa predpis, so navedene v spodnji preglednici. V preglednici se pojavljata dve kategoriji eksplozije. Eksplozivna sredstva kategorije I so eksplozivi s takšno težo, da so nameščeni v vozilih, kategorijo II pa predstavljajo take vrste eksploziva, ki so tako težke, da se jih v bližino+ objektov lahko prinese v rokah. Kontrolirano območje, ki je navedeno v preglednici, je nadzorovano območje. To območje je razdalja od stavbe do tam, kjer poteka nadzor. Kontrolirano območje temelji na predvidevanju, da bodo odkrita vsa eksplozivna sredstva, če jih bodo želeli transportirati na to območje. Če okrog stavbe ni kontroliranega območja, je ena izmed rešitev, da se ceste in parkirišča ne gradijo bližje, kot je za posamezno stavbo določeno z varnostno razdaljo. Pri novejših objektih je dovolj, da se upošteva minimalna razdalja med potencialnim virom eksploziva in objektom. Če gre za starejše objekte in se ne morejo zagotoviti razdalje za običajno konstruirane objekte, ki so navedene v preglednici, se lahko uporabi minimalna razdalja, vendar le, če se z analizo dokaže, da objekt lahko zdrži eksplozijo. Razdalja za običajno grajene objekte se uporablja pri stavbah brez posebne analize. Analizo je treba narediti, če ima objekt tri ali več etaž. S to analizo mora biti ugotovljena razdalja, pri kateri ne bo prišlo do progresivnega rušenja objekta. 


\begin{tabular}{|c|c|c|c|c|c|c|}
\hline \multirow{11}{*}{$\begin{array}{r}\text { Tabela 1: } \\
\text { Varnostna } \\
\text { razdalja za nove } \\
\text { in obstoječe } \\
\text { objekte (UFC } \\
\text { 4-010-01, 2003, } \\
\text { str. } 40 \text { ) }\end{array}$} & \multirow[b]{2}{*}{$\begin{array}{l}\text { Lokacija } \\
\text { eksplozije }\end{array}$} & \multirow[b]{2}{*}{ Vrsta objekta } & \multirow[b]{2}{*}{$\begin{array}{l}\text { Merodajna } \\
\text { stopnja } \\
\text { zaščite }\end{array}$} & \multicolumn{2}{|c|}{ Varnostna razdalja } & \multirow[b]{2}{*}{$\begin{array}{l}\text { Merodajna } \\
\text { eksplozivna } \\
\text { polnitev }\end{array}$} \\
\hline & & & & $\begin{array}{l}\text { Razdalja pri } \\
\text { običajno } \\
\text { konstruiranih } \\
\text { objektih }(\mathrm{m})\end{array}$ & $\begin{array}{l}\text { Minimalna } \\
\text { razdalja (m) }\end{array}$ & \\
\hline & \multirow{3}{*}{$\begin{array}{l}\text { Kontrolirano } \\
\text { območje ali } \\
\text { parkirna mesta in } \\
\text { ceste brez kontrole }\end{array}$} & Vojaški objekti & Nizka & 45 & 25 & I \\
\hline & & Javne stavbe & Nizka & 45 & 25 & 1 \\
\hline & & Stanovanjske stavbe & Zelo nizka & 25 & 10 & 1 \\
\hline & \multirow{3}{*}{$\begin{array}{l}\text { Kontrolirano } \\
\text { območje parkirnih } \\
\text { mest in cest }\end{array}$} & Vojaški objekti & Nizka & 25 & 10 & II \\
\hline & & Javne stavbe & Nizka & 25 & 10 & II \\
\hline & & Stanovanjske stavbe & Zelo nizka & 10 & 10 & II \\
\hline & \multirow{3}{*}{$\begin{array}{l}\text { Zabojniki za } \\
\text { odpadke }\end{array}$} & Vojaški objekti & Nizka & 25 & 10 & II \\
\hline & & Javne stavbe & Nizka & 25 & 10 & II \\
\hline & & Stanovanjske stavbe & Zelo nizka & 10 & 10 & $\|$ \\
\hline
\end{tabular}

Standardi določajo tudi, kako mora biti urejena okolica objekta. Ta mora biti pregledna, kajti oseba, ki bo eksploziv namestila v bližino objekta, eksploziva ne bo namestila tako, da bo na vidnem mestu in ga bodo lahko ljudje odkrili že pred aktivacijo. Okrog stavb mora zato biti v razdalji desetih metrov prostor, ki je pregleden. Znotraj tega prostora ne sme biti zabojnikov za odpadke, saj so ti odlično skrivališče za postavljanje improviziranih eksplozivnih sredstev. Znotraj tega prostora tako ne sme biti ničesar, kar bi omogočilo prekrivanje eksplozivnih sredstev.

Standardi posegajo tudi v dimenzioniranje objektov. Vsi elementi objektov, ki so lahko v prihodnosti cilj bombnih terorističnih napadov, morajo biti dimenzionirani po navodilih za dimenzioniranje takšnih objektov.

Standard posebej obravnava stavbe, ki imajo tri ali več etaž. Glavno nevarnost za tovrstne stavbe predstavlja progresivno rušenje. Take stavbe morajo biti zato načrtovane tako, da zaradi lokalnih poškodb, ki jih lahko povzroči eksplozija, ne pride do progresivnega rušenja celotne stavbe.

\section{ANALIZA OBJEKTA, NA KATEREGA DELUJE EKSPLOZIJA, IN DOLOČITEV VARNOSTNE RAZDALJE}

Za določitev varnostnega območja okrog stavbe, znotraj katerega se ne sme zgoditi eksplozija, je treba narediti analizo stavbe, obremenjeno z obremenitvijo eksplozije. V analizi je treba upoštevati več spremenljivk, kot so različne količine eksploziva, vrste eksploziva, oddaljenosti eksplozije od objekta in kot, pod katerim deluje eksplozija na objekt (Asprone, 2008). Prav tako ima okolica objekta velik vpliv na obremenitev eksplozije, ker se lahko obremenitev eksplozije z različnimi odboji poveča. Na 
obremenitev eksplozije ima velik pomen tudi vpliv oblike objekta, na katerega deluje obremenitev eksplozije. Za analizo moramo povsem poznati konstrukcijo stavbe in če je mogoče, je treba pridobiti vse načrte izvedenih del na stavbi. Iz teh načrtov je razvidno, kateri materiali so bili uporabljeni ter kakšni so armiranje in vse dimenzije vgrajenih gradbenih elementov. Te podatke potrebujemo, da lahko analiziramo odziv objekta na eksplozijo. Analiza temelji na predvidevanjih (Cormie, 2009) vedenja armiranega betona, obremenjenega z obremenitvijo eksplozije.

\subsection{Odziv objekta, obremenjenega z obremenitvijo eksplozije}

Glede na razmerje med trajanjem obremenitve udarnega vala eksplozije in lastnega nihajnega časa konstrukcije (v nadaljevanju povzeto po Mays, 1995) določimo, kako bo eksplozivna obremenitev delovala na konstrukcijo, in sicer statično, dinamično ter impulzivno. Eksplozivno obremenitev približno modeliramo kot trikotno obremenitev, pri čemer je na začetku največja in nato sčasoma pada. Odziv sistema z eno prostostno stopnjo, ki je obremenjen z eksplozivno obremenitvijo, razdelimo na fazo, ki se ujema s trajanjem obremenitev, in na fazo lastnega nihanja.

- Dolga pozitivna faza v primerjavi s trajanjem lastnega nihanja konstrukcije.

Obravnavamo dogodek, pri katerem je čas trajanja pozitivne faze eksplozije veliko daljši od časa lastnega nihanja konstrukcije. Ko je objekt obremenjen z eksplozijo, so maksimalni premiki funkcija obremenitev eksplozije in togost konstrukcije. Maksimalen premik je dosežen, še preden se je obremenitev eksplozije bistveno zmanjšala. V takšnem primeru obremenitev imenujemo kvazistatična obremenitev.

- Kratka pozitivna faza eksplozije $\mathrm{v}$ primerjavi $\mathrm{s}$ trajanjem lastnega nihanja konstrukcije.

V tem primeru je obravnavan dogodek, pri katerem je čas trajanja pozitivne faze eksplozije veliko krajši od časa lastnega nihanja konstrukcije. Obremenitev se je nehala, preden se je objekt odzval nanjo. Večina deformacij se zgodi v času, daljšem od trajanja pozitivne faze eksplozije. Udarni val eksplozije bo minil, še preden se bo objekt odzval. Tak dogodek imenujemo impulzna obremenitev.

- Enako trajanje pozitivne faze obremenitve in lastnega nihajnega časa konstrukcije. $\mathrm{V}$ tem primeru sta trajanje pozitivne faze eksplozije in čas lastnega nihanja konstrukcije približno enaka. Obremenitev ob takšnem režimu imenujemo dinamična obremenitev.

\section{2 Obremenitev eksplozije}

Naslednji korak pri analizi je, da na objekt računsko nanesemo obremenitev eksplozije (Wassef, 2010). Obremenitev je odvisna od več spremenljivk in jo nanesemo za vse mogoče spremenljivke, torej se naredi obremenitev za različne količine eksploziva. Najbolje jo je narediti za tri tipe, in sicer eksploziv v kovčku s 25 kilogrami TNT ${ }^{2}$, za avtomobil bombo z 250 kilogrami TNT in za tovornjak bombo s 1250 kilogrami TNT. Za izračun obremenitev eksplozije se vse vrste eksplozivov računsko pretvorijo $\mathrm{v}$

TNT - trinitrotoluen. 
eksploziv TNT. Vsak eksploziv ima določen koeficient mase eksploziva v primerjavi z eksplozivom TNT. Vir eksplozije postavljamo na različne lokacije, saj eksplozija na objekt z vsake lokacije deluje drugače.

Obremenitev se določa z računalniškim programom A.T.Blast ${ }^{3}$. Program omogoča uporabniku, da določi maksimalno in minimalno razdaljo eksplozije do ploskve, na katero deluje. Uporabnik določi tudi težo eksploziva in kot delovanja eksplozije na izpostavljeno ploskev objekta. Na podlagi danih parametrov nam program izračuna hitrost udarnega vala, čas od detonacije eksplozije do začetka delovanja obremenitve eksplozije na ploskev, tlak eksplozije, impulz eksplozije in čas trajanja delovanja obremenitve. Primeri rezultatov za eksplozijo s polnitvijo 25 kilogramov so prikazani v spodnjem grafu in tabeli. V programu je bilo določeno, naj izračuna rezultate na vsaka dva metra, in sicer od dveh do šestnajst metrov, pri čemer je bil kot delovanja eksplozije na ploskev $0^{\circ}$.

\begin{tabular}{|c|c|c|c|c|c|c|}
\hline \multirow{10}{*}{$\begin{array}{r}\text { Tabela 2: } \\
\text { Prikaz rezultatov } \\
\text { udarnega vala } \\
\text { v tabeli za } 25 \\
\text { kilogramov TNT } \\
\text { (A.T.Blast) }\end{array}$} & Razdalja & Hitrost & $\begin{array}{l}\text { Čas začetka } \\
\text { obremenitve }\end{array}$ & Tlak & Impulz & $\begin{array}{l}\text { Trajanje } \\
\text { obremenitve }\end{array}$ \\
\hline & $(\mathrm{m})$ & $(\mathrm{m} / \mu \mathrm{s})$ & $(\mu s)$ & $(\mathrm{kPa})$ & $(\mathrm{kPa}-\mu \mathrm{s})$ & $(\mu s)$ \\
\hline & 2 & 1,7 & 0,7 & 20747,29 & 4380,58 & 0,42 \\
\hline & 4 & 0,88 & 2,44 & 3334,17 & 1712,86 & 1,03 \\
\hline & 6 & 0,61 & 5,2 & 978,02 & 1031,04 & 2,11 \\
\hline & 8 & 0,5 & 8,8 & 424,72 & 730,57 & 3,44 \\
\hline & 10 & 0,45 & 13,01 & 235,87 & 563,58 & 4,78 \\
\hline & 12 & 0,42 & 17,63 & 153,06 & 457,95 & 5,98 \\
\hline & 14 & 0,4 & 22,54 & 109,9 & 385,28 & 7,01 \\
\hline & 16 & 0,39 & 27,64 & 84,53 & 332,33 & 7,87 \\
\hline
\end{tabular}

3 Računalniški program (ARA Computer Technologies), namenjen določanju parametrov udarnega vala eksplozije. 
Slika 5:

Grafični prikaz

sprememb

tlakov eksplozije

s 25 kilogrami

TNT glede

na razdaljo,

izračunan $s$

programom

A.T.Blast

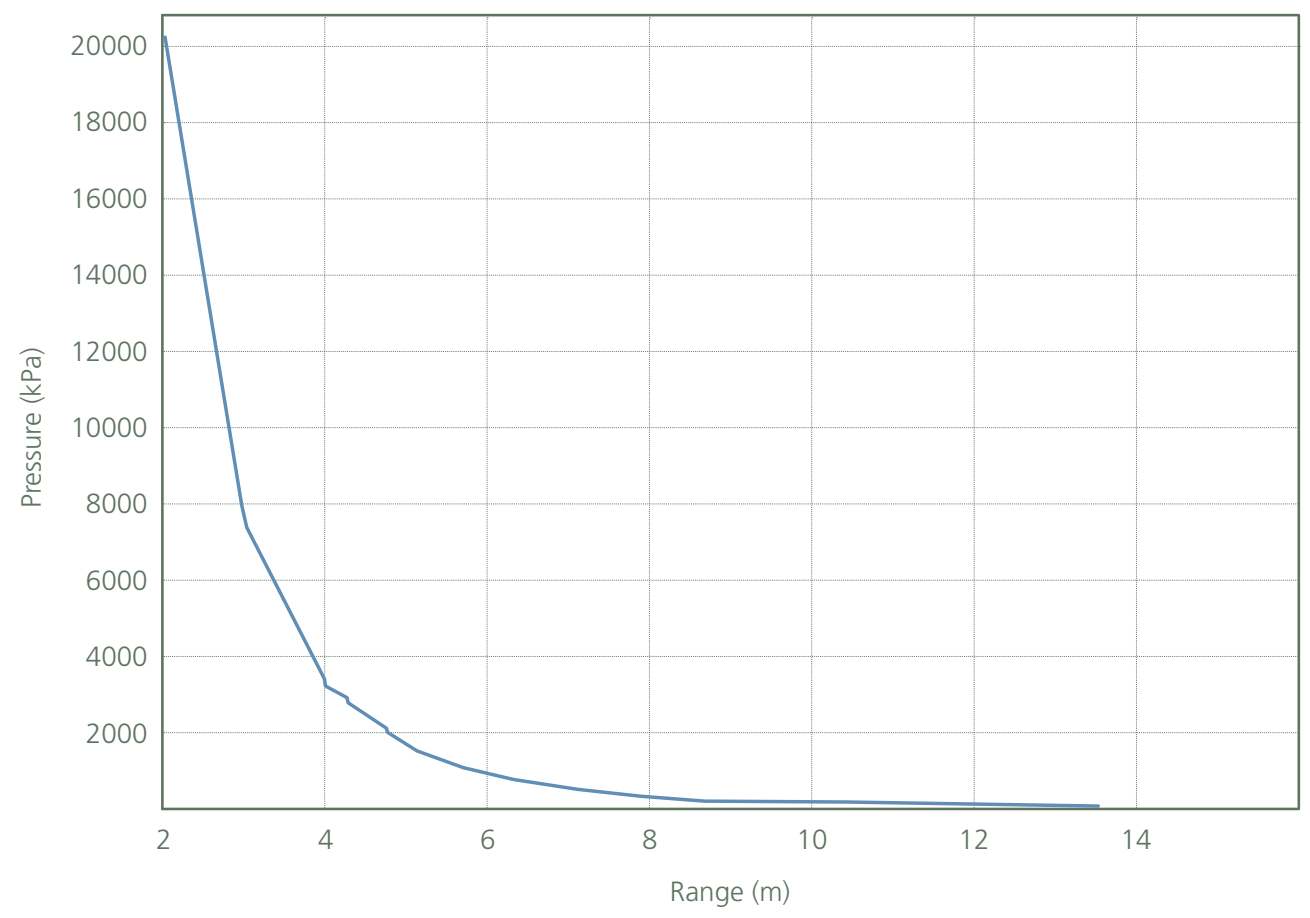

\subsection{Izračun varnostne razdalje med virom eksplozije in objektom}

Cilj te analize je, da ugotovim, kako daleč od stavbe se mora zgoditi eksplozija s 25 , 250 in 1250 kilogrami eksploziva TNT, da ne pride do progresivnega rušenja stavbe.

To razdaljo imenujemo varnostna razdalja.

Slika 6:

Varnostna

razdalja med

virom eksplozije

in objektom,

na katerega

eksplozija deluje

(narisano po

Hinman, 2009)

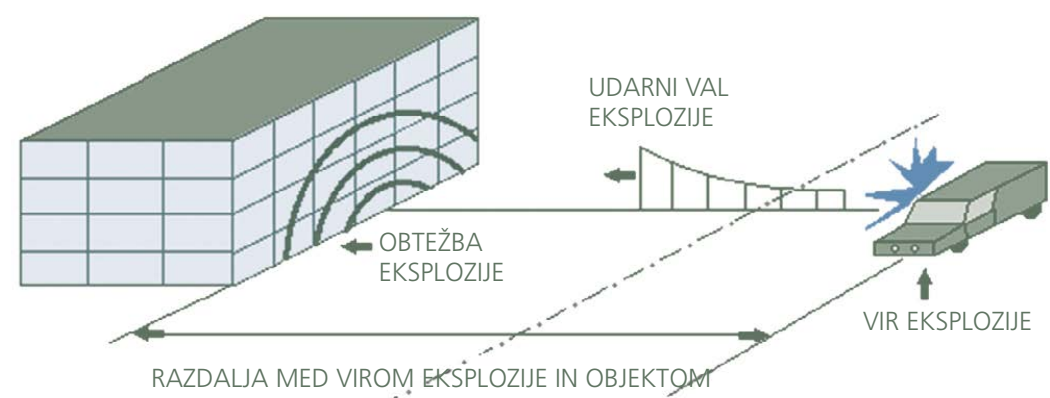

RAZDALJA MED VIROM! EKSPLLZIJE IN OBJEKTOAI

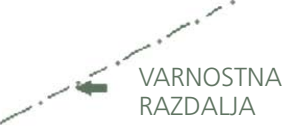


Najprej je treba ugotoviti, rušitve katerih stebrov povzročijo progresivno rušenje stavbe. Za vse prečke objekta se izračunajo mejne vrednosti momentov. V nadaljevanju se določi, kakšno obremenitev eksplozija povzroči na določeni razdalji. Nato se v programu SAP2000 ${ }^{4}$ modelira steber in se ga obremeni z obremenitvijo, ki jo povzroča eksplozija na določeni lokaciji. Steber se nato v programu SAP2000 analizira z modalno analizo. Če je moment, ki ga povzroči obremenitev eksplozije, večji od mejnega momenta, pomeni, da se je steber zrušil. Nato se že modeliranemu objektu v programu SAP2000 smiselno odstranijo stebri in določijo različne kombinacije odstranjenih stebrov. Za vsako kombinacijo odstranjenih stebrov se naredi statična analiza stavbe. Po končani statični analizi se preverijo vse notranje sile, ki jih povzročajo lastna, stalna in spremenljiva obremenitev. Preveri se, ali so presežene mejne vrednosti notranjih sil v posameznih elementih. Za elemente, pri katerih so presežene mejne vrednosti notranjih sil, se predvideva, da so porušeni, zato se jih odstrani. Ponovno se naredi statična analiza, če so bile mejne vrednosti $\mathrm{v}$ drugih elementih presežene, pa pomeni, da je zaradi lokalne rušitve določenih stebrov prišlo do progresivnega rušenja objekta. $\mathrm{S}$ to analizo se tako dobijo vse kombinacije porušenih stebrov, ki povzročijo progresivno rušenje stavbe.

Če je bila obremenitev na tej lokaciji postavitve vira eksplozije tolikšna, da poruši takšno kombinacijo stebrov, da pride do progresivnega rušenja stavbe, pomeni, da je treba izbrati novo lokacijo postavitve vira eksplozije. Ta lokacija se izbere na večji razdalji in se še enkrat naredi celotna analiza. Postopek ponavljamo toliko časa, da pridemo do razdalje, na kateri ne pride več do rušenja stavbe, tako pa dobimo varnostno razdaljo med virom eksplozije in stavbo.

\subsection{Primer analize stavbe, ob kateri se zgodi eksplozija}

V nadaljevanju bom opisal primer analize delovanja eksplozije avtomobila bombe, kar ustreza 250 kilogramom TNT, na stavbo, oddaljeno 22 metrov. Obravnaval sem poslovno-stanovanjsko zgradbo, ki ima poleg pritličja še tri etaže. Predvidel sem, da je na fasadi stavbe lamelirano steklo, zato se vsa obremenitev eksplozije prenese na armiranobetonsko konstrukcijo. Arhitektura stavbe je prikazana na sliki 7. Stavba je dimenzionirana (Beg, 2009) skladno z evrokodom.

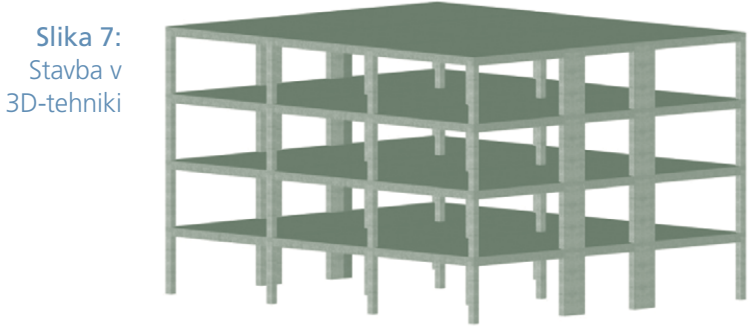

4 Program SAP2000 je profesionalen programski paket za linearno ali nelinearno analizo in dimenzioniranje konstrukcij in konstrukcijskih sistemov. 
Cesta je 22 metrov oddaljena od stavbe, zanimalo pa me je, ali pride ob eksploziji avtomobila bombe do progresivnega rušenja stavbe. Analizo sem naredil za različni lokaciji eksplozije. V primeru A delovanja eksplozije na stavbo sem predvidel, da se eksplozija zgodi na cesti pravokotno ob robu stavbe. V primeru B delovanja eksplozije na stavbo sem predvidel, da se eksplozija zgodi na cesti pravokotno na sredino stavbe.

Slika 8:

Tloris lokacije eksplozije (levo primer A, desno primer B)

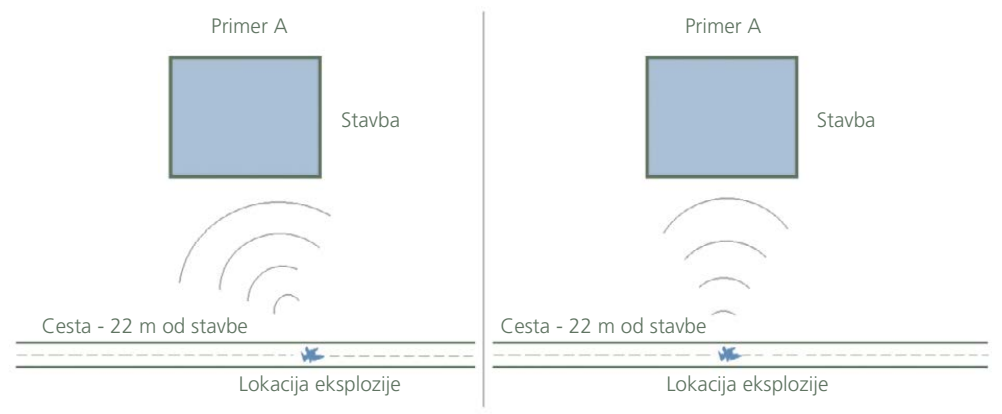

Rezultati analize v primeru A. Delovanje obremenitve udarnega vala je prikazano na sliki 9. V tovrstnem primeru je obremenitev eksplozije porušila le najbolj obremenjen steber, kar pa ne povzroči progresivnega rušenja stavbe.

Slika 9:

Obremenitev eksplozije na fasado stavbe $v$ primeru $A$

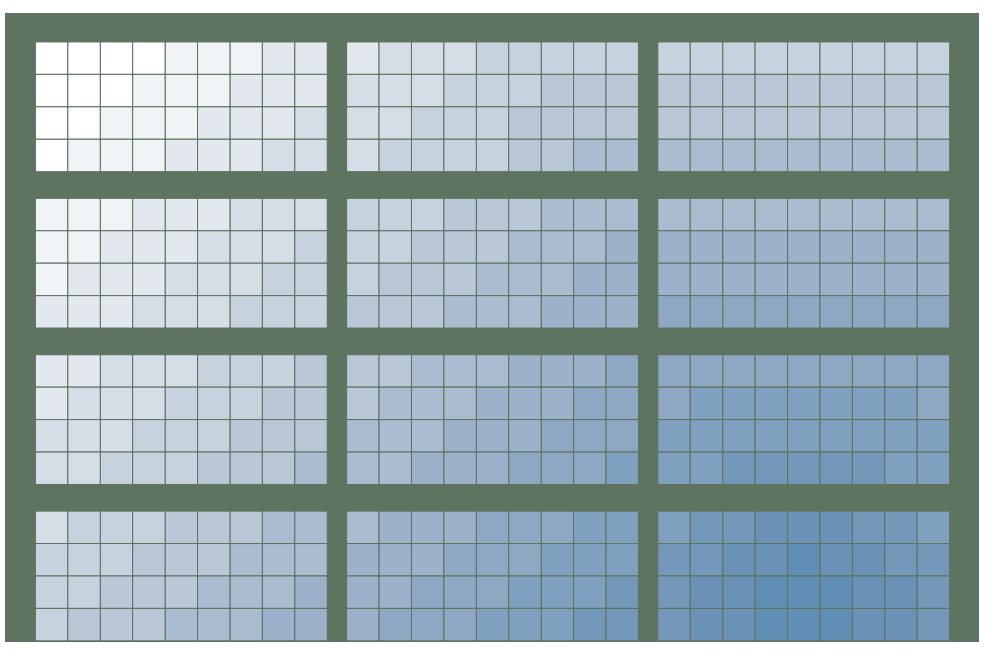


Rezultati analize v primeru B. Delovanje obremenitev udarnega vala je prikazano na sliki 10. V tovrstnem primeru je obremenitev eksplozije porušila takšno kombinacijo stebrov, da pride do progresivnega rušenja stavbe.

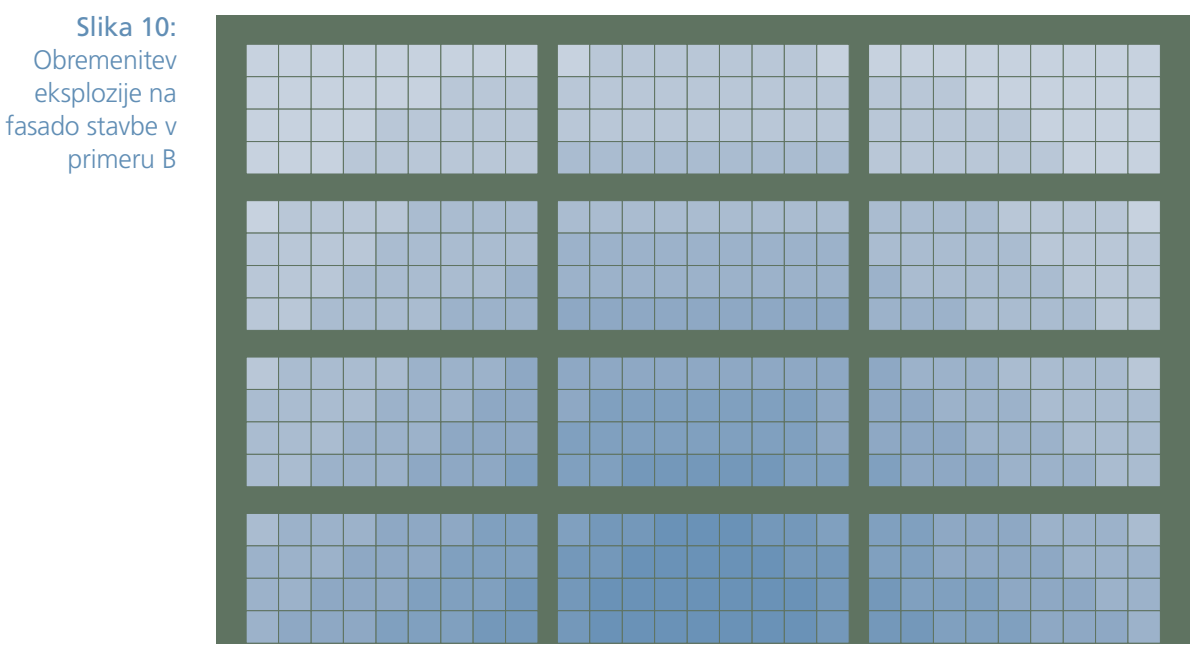

$220215210200190180170160150 \quad \mathrm{KPa}$

Zgornja analiza je pokazala, da bi bile posledice eksplozije avtomobila bombe $\mathrm{v}$ primeru B za stavbo katastrofalne. V primeru A ne pride do rušenja stavbe, ker udarni val deluje pod večjim kotom kot v primeru B in je posledično obremenitev v primeru A manjša. V primeru A je tudi razdalja med virom eksplozije in skrajno točko na fasadi, na katero udarni val deluje, večja kot v primeru B. To pomeni, da je v primeru A zato tudi obremenitev nekoliko manjša kot v primeru B, saj udarni val z večjo razdaljo slabi. Posledično udarni val v primeru A povzroči prav toliko manjšo obremenitev od udarnega vala $\mathrm{v}$ primeru $\mathrm{B}$, da ne povzroči progresivnega rušenja stavbe.

\section{5 Ukrepi za zagotavljanje varnostnega območja okrog stavbe}

Najučinkovitejši ukrep, s katerim zagotovimo varnostno območje okrog stavbe, je preureditev okolice. Okolica se preuredi tako, da se onemogoči dostop z vozili na varnostno območje, zato posledično vozilo z eksplozivom ne more v takšno bližino objekta, da bi se zaradi eksplozije rušile stavbe. Na sliki 10 je prikaz preureditve okolice objekta po opravljeni analizi vpliva eksplozije in določitvi varnostnega območja. Na levi strani slike vidimo prvotno stanje okolice stavbe in z rdečim kvadratom določeno območje, na katerem ne sme priti do eksplozije. Z oranžno barvo je označen del parkirišča in ceste, ki posega na varnostno območje. Na desni strani slike je okolica po analizi stavbe preurejena, tako da se znotraj varnostnega 
območja vozila ne morejo voziti in parkirati. Parkirna mesta se prestavijo zunaj varnostnega območja, prav tako se tudi cesta premakne zunaj varnostnega območja (povzeto po UFC 4-010-01, 2003).

\footnotetext{
Slika 11: Prikaz

preureditve

okolice objekta

po opravljeni

analizi vpliva

eksplozije

in določitvi

varnostnega

območja

(pripravljeno po

UFC 4-010-01,
}

2003)
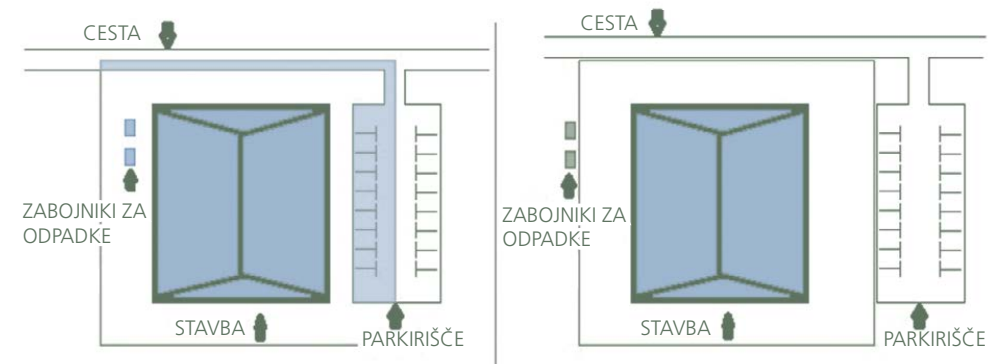

Sklep Uporabljena metodologija določanja vpliva eksplozije na objekte vsebuje nekatere pomanjkljivosti, in sicer ni upoštevana komponenta srka obremenitve in lege sosednjih objektov, predvidena sta idealna sferična eksplozija in le en dogodek, torej eksplozija, plošče konstrukcije so bile obravnavane kot idealno toge itn., vendar je s stališča inženirskega pristopa dovolj natančna za definiranje varnostne razdalje za obravnavani objekt.

Živimo v času, ko skoraj ne mine dan, da ne bi mediji poročali, da se je nekje v svetu zgodil bombni teroristični napad. Če bi želeli povečati varnost sedanjih stavb, ki jih potencialno ogroža bombni teroristični napad, bi morali vsako potencialno ogroženo stavbo analizirati glede vpliva eksplozije. Iz rezultatov analize bi dobili določeno varnostno območje okrog stavbe, ki bi ga morali nadzirati fizično ali s tehničnimi ukrepi.

\section{Literatura}

1. Asprone, D., Jalayer, F., Prota, A., Manfredi, G. 2008. Proposal of a probabilistic model for multi-hazard risk assessment of structures in seismic zones subjected to blast for the limit state of collapse: 10 str. http://wpage.unina.it/fatemeh.jalayer/Publications_file/ SSBlast.pdf, 27. 10. 2010.

2. Beg, D., Pogačnik, A. 2009. Priročnik za projektiranje gradbenih konstrukcij po evrokod standardih. Ljubljana, Inženirska zbornica Slovenije: str. 1077

3. Bosiljkov, V., Gostič, S., Kržan, M., Antolinc, D., Žarnić, R. Izdelava in demonstracija modela za načrtovanje ohranjanja umetnostnozgodovinske dediščine v vojnih spopadih: končno poročilo za CRP MIR M4-0207. Ljubljana: UL FGG: ZRMK Inštitut, 2009.

4. Carino, N., Lew, H. 2001. Summary of NIST/GSA Workshop on Application of Seismic Rehabilitation Technologies to Mitigate BlastInduced Progressive Collaps. 17 str. http:// www.fire.nist.gov/bfrlpubs/build01/PDF/b01055.pdf, 24. 1. 2011.

5. Cormie, D., et al. 2009. Blast effects on buildings Second edition. London, Thomas Telford Limitd, 40 Marsh Wall, London E14 9TP: str. 255 
6. Glasstone, S., Dolan, P. 1977. Effects of nuclear weapons.

7. Hinman, E., 2009. Blast Safety of the Building Envelope. http://www.wbdg.org/resources/ env_blast.php, 15. 10. 2010.

8. Mays, G., Smith, P. 1995. Blast effects on buildings. London, Thomas Telford Publications, Thomas Telford Services Ltd, 1 Heron Quay, London E14 4JD.

9. SIST EN 1991-1-7: 2006, Evrokod 1: Vplivi na konstrukcije - 1-7 del: Splošni vpliviNezgodni vplivi.

10. SIST EN 1998-1: 2005, Evrokod 8: Projektiranje potresnoodpornih konstrukcij-del 1: Splošna pravila, potresni vplivi in vplivi na stavbe.

11. Wassef, W., et al. 2010. Blast-Resistant Highway Bridges, Design and Detailing Guidelines. Washington, Transportation research board: 143 str. http://onlinepubs.trb.org/ onlinepubs/nchrp/nchrp_rpt_645.pdf, 11. 12. 2010.

12. UFC 4-010-01. 2003. DoD Minimum Antiterrorism Standards for Buildings: http://www. wbdg.org/ccb/DOD/UFC/ufc_4_010_01.pdf, 27. 1. 2011. 